\title{
Novel Approach for Determination of Generator Contribute in Transmission Usage Based On the Average Tracing Method
}

\author{
Syarifuddin Nojeng ${ }^{1}$, Syamsir ${ }^{1}$, Muhammad Nawir ${ }^{1}$ and Mohammad Yusri Hassan ${ }^{2}$ \\ ${ }^{1}$ Electrical Department of Engineering Faculty-Universitas Muslim Indonesia \\ ${ }^{2}$ Centre of Electrical Energy Systems (CEES)-Universiti Teknologi Malaysia
}

\begin{abstract}
This paper is a study to solved the problem of the utilization of transmission by using some method of transmisision usage allocate. In a deregulated power system required method of determining the actual power flow on each line of the generator to load. The main purpose of this paper is to provide an overview of the use of the average approach to determining of generator contribute of the transmission line open access in electricity market deregulation around the world. Based on the 6 bus Graver's system test showing that proposed method can provide option method for allocating the use of transmission line for all generator.
\end{abstract}

Keywords-generator contribute; transmision usage; average tracing method; deregulated power system

\section{INTRODUCTION}

Deregulation of the electricity industry is undergoing changes with applied transmission open access system that separates ownership of each component of the generation, transmission and distribution in the business and then subsequently managed in a transparent, accountable and fair to all players [1]. under deregulation, the user subscribing the interconnection network has to pay the cost of the transmission service, and this cost is determined based on the utilization of the transmission line [2]. transmission usage allocating is more significant in the implementation of usage-based cost allocation in deregulated power system. the impact of each user in line flow is essential for introduce a competitive pricing strategy that incentivizes the all user the system load as well as satisfies the transmission owner. then to recover the total transmission network cost, so the recovery of transmission system cost should be in a fair and equitable manner that takes into account the user helping in reducing the line capacity by counter-flow effect each transaction. transmission usage allocating also required that transmission losses should be as accurate as possible assigned among all network users. transmission loss allocation is important in order to meet between demand and for the transmission owner as well. meanwhile, it can to minimize locational charge for the user creating counter-flow for alleviating the transmission network. transmission open access is gaining attention in countries that desire to introduce competition into traditional cost-of-service regulated utilities [3]. transmission open access is not an end; rather, it is a critical means for achieving that objective. this paper has two primary objectives. the first is to discuss methods of evaluating and costing transmission services. the second is to outline management and operational issues under the new deregulated paradigm that the industry is actually facing today. the use of system allocation is very important for deregulated power system and energy market in over the world. in the existing methods so far, transmission usage allocate method can be classified into two paradigm are power tracing and using sensitivity [4], drpt -2008]. these factors have been the most popular techniques presently in use in electrical power system for calculation of transmission usage and related due to its simplicity in methodology, linearity and applications.

\section{TRANSMission USAgE METHOD}

First time, the allocation of transmission usage method is presented is the distribution factors by Hugh Rudnick, Rodrigo Palma and Enrique Fernandez [5]. This method is can be to implementing for purpose of allocating payments to users of the transmission network with define; Generalized Shift Distribution Factors (GSDFs) or A Factors, Generalized Generation Distribution Factors (GGDFs) or D Factors, and Generalized Load Distribution Factors (GLDFs) or C Factors are the three factors associated with this approach. An approach for tracing power flow based on proportional sharing principle using Bialek Method. Based on electricity theorem, is indistinguishable and each of the outflows down the line from node $\mathrm{i}$ is dependent only on the voltage gradient and impedance of the line, so it may be assumed that each MW leaving the node contains the same proportion of the inflows as the total nodal flow i P . Bialek Tracing Algorithm Method has two algorithm which are; upstream and downstream algorithm. The upstream algorithm allocated contribute individual generator in each line transmission. While, the downstream algorithm is using to determine in each transmission usage/supplement charge for individual loads [6-7]. This method most common but its main drawback is that the shares are always positive; i.e., no counterflows are encountered and all the charges to the network participant are positive. Then, Kirschen proposed an approach based on proportional sharing principle using Graph method [8]. According with the active power flows obtained from the results of power flow study, the method introduces new concepts of domain-domain generator, common, and link. The domain of a generator is defined as the set of buses which are reached by the power produced by same generator. A common is defined as a set of neighboring buses supplied by the same generators and the rank of a common is defined as the number of generators supplying power to the buses with compare this common. Having divided the buses into commons, 
each branch is either internal to a common (i.e., it connects two buses which are part of the same common) or external (i.e., it connects two buses which are part of different commons). This approach the state of the system that can be represented by a directed, a cyclic graph if the commons are represented as nodes and the links as branches. This graph is directed because the direction of the flow in a link is specified. It is a cyclic because links can only go from a common supplied by fewer generators to a common supplied by more generators [9]. The disadvantage of this method is that the contribution of each generator for each 'common' (i.e., the set of buses supplied from the same set of generators) is assumed to be the same as well as it ignores the counter-flow within the network. Gubina introduce a new method for determining the contributions of generators in a customer load based on the Nodal Generation Distribution Factors (NGDF). This method without use the system matrices for determining the share of each generator in the particular line power flow [10]. Based on a search algorithm for power flow directions and the matrix calculations are not required. This method is based on the proportional sharing, it only allocates the share in the positive direction and this seems to be unfair to the network users. An analytical model has been proposed for tracing power flow to avoid expansion matrix [11]. The construction approach and properties of extended incidence matrix (EIM) are developed. By using results of an AC or DC power flow solution from any off-line program or state estimation, the extended incidence matrix, generation and load power vectors, and distribution factor matrix are derived so that the analytical model of power transfers between generators and loads can be built. The major advantage of this method is that no proportional sharing assumption on the flow distribution is needed. The main drawback of the approach is the fact that it gives the same results with the proportional methods.

\section{Proposed Method}

By defined the line transmission in line- $j$ is $f_{i}$ for each generator, we can formulate is following that:

$$
P_{L j}=\sum_{k=1}^{n} P_{G_{k}, f_{i}}=P_{G_{1}, f_{i}}+P_{G_{2}, f_{i}}+\ldots+P_{G_{k}, f_{i}}
$$

Therefore, we obtain the general formula for all existing method to determine of transmission usage allocate as follows:

$$
P_{L_{j}}=\sum_{k=1}^{n} P_{G_{k}, f_{i}}=\sum_{k=1}^{n} P_{G_{k}, f_{2}}=\sum_{k=1}^{n} P_{G_{k}, f_{n}}
$$

By using an average approach, can be calculate the power flow due generator contribute in each line as follows:

$$
F_{L j, G i}=\frac{\sum_{\substack{j \in L \\ n \in f_{n}}} P_{L j, f n}}{n}
$$

Where:

$F_{L j, G i}=$ Average power flow due generator $-\mathrm{i}$ in line $\mathrm{j}$

$F_{L j, f n}=$ Power flow due generator $-\mathrm{i}$ in line-j using existing method.

$n=$ Number of existing method

\section{CASE STUdy AND Discussion}

\section{A. Case Study}

The 6-bus Graver's test system shown in Figure 1 and its line data tabulated in Table 1 and Table 2.

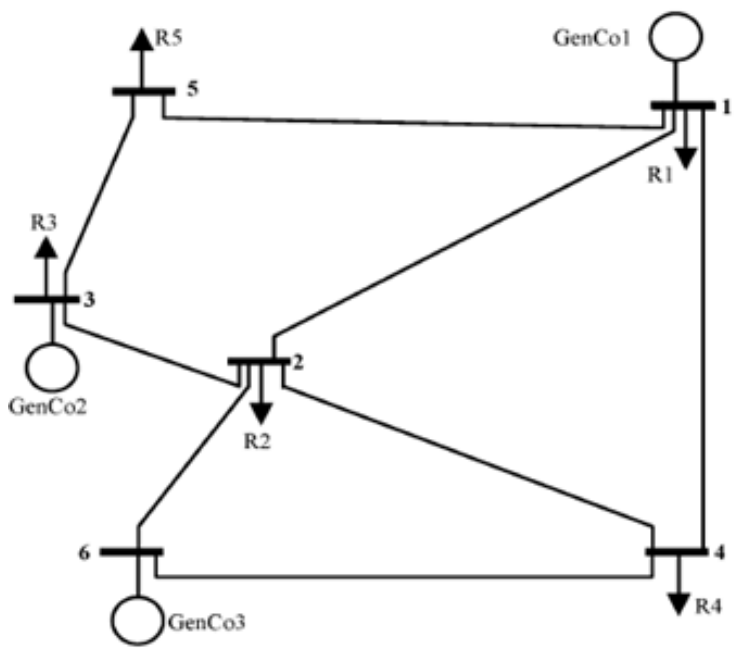

FIGURE I. SINGLE LINE DIAGRAM OF THE SIX BUS GRAVER'S TEST SYSTEM

TABLE I. LINE DATA

\begin{tabular}{|l|l|l|l|}
\hline From & To & $\mathrm{X}_{\mathrm{L}}(\mathrm{ohm}), \mathrm{pu}$ & $\mathrm{L}(\mathrm{km})$ \\
\hline 1 & 2 & 0.4 & 40 \\
\hline 1 & 4 & 0.6 & 60 \\
\hline 1 & 5 & 0.2 & 20 \\
\hline 2 & 3 & 0.2 & 20 \\
\hline 2 & 4 & 0.4 & 40 \\
\hline 3 & 5 & 0.1 & 20 \\
\hline 2 & 6 & 0.15 & 30 \\
\hline 4 & 6 & 0.15 & 30 \\
\hline
\end{tabular}

TABLE II. BUS DATA

\begin{tabular}{|c|c|c|}
\hline Number of bus & Generating, $\mathrm{P}_{\mathrm{G}}(\mathrm{MW})$ & Load $(\mathrm{MW})$ \\
\hline 1 & 150 & 80 \\
\hline 2 & 0 & 240 \\
\hline 3 & 333.19 & 40 \\
\hline 4 & 0 & 160 \\
\hline 5 & 0 & 240 \\
\hline 6 & 276.80 & 0 \\
\hline
\end{tabular}

\section{B. Discuss}

From case study using the Six-bus Graver's test systems show that the contribution generator in each line using Bialek, Kirschen, Graph theory and Extended Incidence Matrix (EIM) are almost the same as the methods share the proportional sharing principle. Contrast, using Distribution Factor Method 
(GSDF factor) can be showing effect counter flow. For instance; In the 6-bus system, the methods Bialek result in zero charging for G3 and G6 and full responsibility of G1 to the use of lines $1-2,1-4,1-5$, and $3-5$. In appendix-I, it is clear that the two methods result in zero charging for G1 to the use of lines 1-5, 3-5, 6-2 and 6-4 (i.e. the transmission owner will be receives zero transmission revenue as the methods trace zero MW for using the lines by G1).

\section{CONCLUSION}

Based on the result of the contributions generator to the loads and flows in the power system network has become an main issue since the deregulation of the electric power system. It is necessary for the operation of the system, congestion management, competition of transmission pricing, ancillary services and related issues. The proposed method, which applies based average tracing approach, has shown in allocating the transmission usage in a fair manner. The results, tested on the 6-bus system, indicated that there were differences of transmission usage, which in clearly due generator contribute. This proposed method can be further extended by considering transmission pricing.

\section{ACKNOWLEDGMENT}

This paper was support facilities by Electrical Machines Laboratory-Universitas Muslim Indonesia and Centre of Electrical Energy Systems (CEES) University Teknologi Malaysia.

\section{REFERENCES}

[1] Lai L. L. Power System Restructuring and Deregulation. John Wiley and Sons,Ltd., New York. 2001.

[2] Syarifuddin Nojeng, Mohammad Yusri Hassan, Dalila Mat Said, Md. Pauzi Abdullah, Faridah Hussin, Member, IEEE. Improving the MWMile Method Using the Power Factor-Based Approach for Pricing the Transmission Services. IEEE Trans. Power System. 2014.29 (5): 20442048.

[3] Ilic, M.On the objectives of transmission pricing under open access.Power Engineering Society. Winter Meeting.February. 1999.

[4] Rudnick H., Palma R., and Fernandez J. E. Marginal pricing and supplement cost allocation in transmission open access. IEEE Trans. Power System. 1995.10 (2): 1125-1142.

[5] Bialek J. Tracing the flow of electricity. IEE proc. Gener. Transm. Distrib.1996. 143 (4): 313-320.

[6] Bialek J. Topological generation and load distribution factors for supplement charge allocation in transmission open access. IEEE Trans. Power Systems1997. 12(3): 1185-1193.

[7] Bialek J., and Tam D. B. Tracing the generators' output. Opportunities and Advances in International Electric Power Generation, International Conference. 1996. 419: 133-136.

[8] Kirschen, D., Allan, R., and Strbac, G. Contributions of individual generator to loads and flows. IEEE Trans. Power System. 1997. 12 (1): 52-60.

[9] Starbac G., Kirschen D., and Ahmed S. Allocating transmission system usage on the basis of traceable contributions of generators and loads to flows. IEEE Trans. Power System. 1998. 13 (2): 527-534.

[10] Gubina F., Grgic D., and Banic I. A method for determining the generators' share in a customer load. IEEE Trans. Power Systems. 2000. 15 (4): 1376- 1381

[11] Xie K., Zhou J., and Li W. Analytical model and algorithm for tracing active power flow based on extended incidence matrix. Electric Power System Research. 2009. 79: 399-405.

TABLE III. COMPARISON OF EXISTING METHOD WITH PROPOSED METHOD

\begin{tabular}{|c|c|c|c|c|c|c|c|c|c|c|c|}
\hline \multicolumn{2}{|c|}{ Line flow } & & \multicolumn{3}{|c|}{ GGDF Method } & \multicolumn{3}{c|}{ Bialek Method } & \multicolumn{3}{c|}{ Propose Method } \\
\hline From & To & $\begin{array}{c}\text { Total Load } \\
\text { Flow(MW) }\end{array}$ & $\begin{array}{c}\text { G1 } \\
\text { (MW) }\end{array}$ & $\begin{array}{c}\text { G3 } \\
\text { (MW) }\end{array}$ & $\begin{array}{c}\text { G6 } \\
(\mathrm{MW})\end{array}$ & $\begin{array}{c}\text { G1 } \\
(\mathrm{MW})\end{array}$ & $\begin{array}{c}\text { G3 } \\
(\mathrm{MW})\end{array}$ & $\begin{array}{c}\text { G6 } \\
(\mathrm{MW})\end{array}$ & $\begin{array}{c}\text { G1 } \\
(\mathrm{MW})\end{array}$ & $\begin{array}{c}\text { G3 } \\
(\mathrm{MW})\end{array}$ & $\begin{array}{c}\text { G6 } \\
(\mathrm{MW})\end{array}$ \\
\hline 1 & 2 & 16,59 & 41,24 & 5,37 & $-30,02$ & 16,6 & 0 & 0 & 28,92 & 2,68 & $-15,01$ \\
\hline 1 & 4 & 13,40 & 28,40 & 18,37 & $-33,37$ & 13,4 & 0 & 0 & 20,90 & 9,18 & $-16,68$ \\
\hline 1 & 5 & 40 & 64,57 & $-58,83$ & 34,25 & 40 & 0 & 0 & 52,28 & $-29,41$ & 17,13 \\
\hline 3 & 2 & 93,19 & 9,307 & 151,6 & $-67,72$ & 0 & 93,19 & 0 & 4,65 & 122,39 & $-33,86$ \\
\hline 2 & 4 & 3,51 & 1,36 & 22,18 & $-20,04$ & 0,24 & 1,34 & 1,93 & 0,80 & 11,76 & $-9,05$ \\
\hline 3 & 5 & 200 & $-17,20$ & 164,05 & 53,15 & 0 & 200 & 0 & $-8,60$ & 182,02 & 26,57 \\
\hline 6 & 2 & 133,72 & $-1,81$ & $-29,58$ & 165,1 & 0 & 0 & 133,7 & $-0,91$ & $-14,79$ & 149,4 \\
\hline 6 & 4 & 143,08 & 1,81 & 29,58 & 111,7 & 0 & 0 & 143,1 & 0,91 & 14,79 & 127,4 \\
\hline
\end{tabular}

